Proceedings

\title{
Genome Sequence Analysis and Insecticidal Characterization of Bacillus thuringiensis Bt-UNVM_94, a Strain Showing Dual Insecticidal Activity against Lepidopteran and Coleopteran Pests
}

\author{
Cecilia Peralta ${ }^{1}$, Diego Herman Sauka ${ }^{2}$, Melisa Pérez ${ }^{2}$, María Ines Onco 2 , Angelika Fiodor 3, Javier Caballero ${ }^{4,5}$, \\ Primitivo Caballero ${ }^{4,5}$, Colin Berry ${ }^{6}$, Eleodoro E. Del Valle ${ }^{7}$ and Leopoldo Palma ${ }^{1,8, *}$
}

Citation: Peralta, C.; Sauka, D.H.; Pérez, M.; Onco, M.I.; Fiodor, A.; Caballero, J.; Caballero, P.; Berry, C.; Del Valle, E.E.; Palma, L. Genome Sequence Analysis and Insecticidal Characterization of Bacillus thuringiensis Bt-UNVM_94, a Strain Showing Dual Insecticidal Activity against Lepidopteran and Coleopteran Pests. Proceedings 2021, 65, x. https://doi.org/10.3390/xxxxx

Received: 5 November 2020 Accepted: 13 January 2021 Published: 14 January 2021

Publisher's Note: MDPI stays neutral with regard to jurisdictional claims in published maps and institutional affiliations.

Copyright: (C) 2021 by the authors. Submitted for possible open access publication under the terms and conditions of the Creative Commons Attribution (CC BY) license (http://creativecommons.org/licenses /by/4.0/).
1 Centro de Investigaciones y Transferencia de Villa María (CIT-VM), Consejo Nacional de Investigaciones Científicas y Técnicas (CONICET), Universidad Nacional de Villa María, 5900 Villa María, Argentina; ceci036@gmail.com

2 Instituto Nacional de Tecnología Agropecuaria (INTA), Instituto de Microbiología y Zoología Agrícola (IMYZA), 1712 Castelar, Argentina; sauka.diego@inta.gob.ar (D.H.S.); perez.melisa@inta.gob.ar (P.M.); onco.mines@inta.gob.ar (M.I.O.)

3 Department of Biology, Institute of Microbiology, Bialystok University, 15097 Bialystok, Poland; angelikafiodor@gmail.com

4 Institute for Multidisciplinary Research in Applied Biology-IMAB, Universidad Pública de Navarra, 31192 Mutilva, Navarra, Spain; javier.caballero@unavarra.es (J.C.); pcm92@unavarra.es (P.C.)

5 Bioinsectis SL, Avda Pamplona 123, Mutilva, Navarra, Spain

6 Cardiff School of Biosciences, Cardiff University, Park Place, Cardiff, CF10 3AX, UK; berry@cardiff.ac.uk

7 Facultad de Ciencias Agrarias, Universidad Nacional del Litoral, 3080 Esperanza, Santa Fe, Argentina; eleodoro77@gmail.com

8 Instituto Académico Pedagógico de Ciencias Básicas y Aplicadas (IAPCByA), Universidad Nacional de Villa María (UNVM), 5900 Villa María, Argentina

* Correspondence: palma.leopoldo@gmail.com; Tel.: +54-(0353)-4539100 then 3068; Fax: +54-(0353)-4539117

\begin{abstract}
Bacillus thuringiensis (Bt) is a gram-positive and spore-forming bacterium that synthesizes a wide diversity of proteins with insecticidal activity and which has demonstrated its potential and safety as a biocontrol agent for more than four decades. However, several susceptible insect species have been reported for evolving resistance, which demands screening for strains exhibiting novel insecticidal properties. In this work, we performed the genome sequence analysis and insecticidal characterization of a Bt strain designated Bt-UNVM_94, isolated from Argentina. Its genomic sequence harbours one coding sequence showing homology to the crystal protein Cry7Ga1 plus two others showing similarity to Mpp2Aa3 (ETX/Mtx2) protein and a putative mosquitocidal protein (NPP1). Cry7A and Cry7B are known to be distinctively active against some coleopteran and lepidopteran larvae, respectively. Spore-crystal mixtures used for SDS-PAGE analysis showed a band corresponding to the predicted size of Cry7Ga-like protein $(\sim 128 \mathrm{kDa})$. Bioassays performed also with spore-crystal mixtures exhibited dual toxicity with $50 \%$ and $91 \%$ mortality against Cydia pomonella (Lepidoptera: Tortricidae) and Anthonomus grandis (Coleoptera: Curculionidae), respectively, representing that we believe the first insecticidal activity report for a Cry7Ga-like protein. Screenings of novel Bt strains may provide proteins with novel insecticidal properties that can be used to suppress insect resistance to the most used Bt-crops in agriculture.
\end{abstract}

Keywords: Bacillus thuringiensis; crystal proteins; Cry7 proteins; insecticidal activity; lepidopteran and coleopteran pests

Key Contribution: In this work we report for the first time; the insecticidal activity of a Cry7Ga-like protein from Bacillus thuringiensis 


\section{Introduction}

Bacillus thuringiensis (Bt) is the best studied gram-positive entomopathogenic bacterium with many strains bearing plasmids that contain a wide variety of genes encoding insecticidal proteins. This has bestowed Bt-based products as the most marketed microbial insecticides to date [1]. Crystal and cytolytic (Cyt) proteins are the best characterized group of insecticidal proteins, and are synthesized during the stationary growth phase as crystalline-parasporal inclusions showing toxicity against a wide range of invertebrates [2-4]. Crystal proteins may be classified into several distinct groups according to their homology and molecular structure [5]. The largest group is composed by the so-called three-domain Cry proteins followed by Mpp, Tpp and other structural families including Mpp2 (formerly Mtx2) and Tpp1/Tpp2 (formerly BinA/BinB) proteins typically produced by Lysinibacillus sphaericus [6]. Three-domain Cry proteins are mainly toxic for lepidopteran, dipteran, coleopteran, hymenopteran larvae and nematodes $[3,4,7]$. These proteins exhibit two different sizes of $\sim 70$ to $\sim 130 \mathrm{kDa}$, generating smaller protease stable fragments upon proteolytic activation of their active forms [7,8]. L. sphaericus Tpp1/Tpp2, Mpp and Mtx proteins are toxic against some dipteran larvae whereas Tpp and Mpp proteins from Bt may be toxic for coleopteran and dipteran species [6].

Since Bt-based biopesticides were first commercialized in France around 1940 [9], the identification of novel insecticidal genes encoding insecticidal proteins spanning wider ranges of insect orders has been continuously increasing [10-12]. However, most of the Bt strains and the insecticidal proteins used are known to be highly active against lepidopteran pests [13]. Strains showing toxic activity against coleopterans are limited and may encode three-domain Cry7 proteins, which have shown distinct toxicity against some coleopteran (Cry7A) and lepidopteran (Cry7B) pests [3]. The finding of novel Bt strains producing different insecticidal proteins opens the possibility of discovering insecticidal proteins that could be used not only for controlling a wider range of insects but also for delaying insect resistance [14]. This work aimed to perform the genome sequencing and insecticidal characterization of a novel Bt strain, designated Bt-UNVM_94, isolated from Cululú, Santa Fe province (Argentina).

\section{Results}

\subsection{Strain Isolation and Characterization}

Bt-UNVM_94 colonies exhibited the typical Bt morphology on nutrient agar with matte-white colour, flat, dry and with uneven borders. Microscopic analysis revealed the presence of Commassie-blue stained parasporal crystals (Figure 1A) that were later confirmed as rhomboidal-shaped crystals by using Scanning Electron Microscopy [15].

Protein patterns revealed that strain Bt-UNVM_94 produced a main band of $~ 130$ $\mathrm{kDa}$ that comigrates along with Cry1 and Cry4 bands from Bt svar. kurstaki (strain HD1) and Bt svar. israelensis (strain HD-567), respectively (Figure 1B), which was consistent with the predicted Cry7Ga-like molecular weight of $\sim 128 \mathrm{kDa}$.
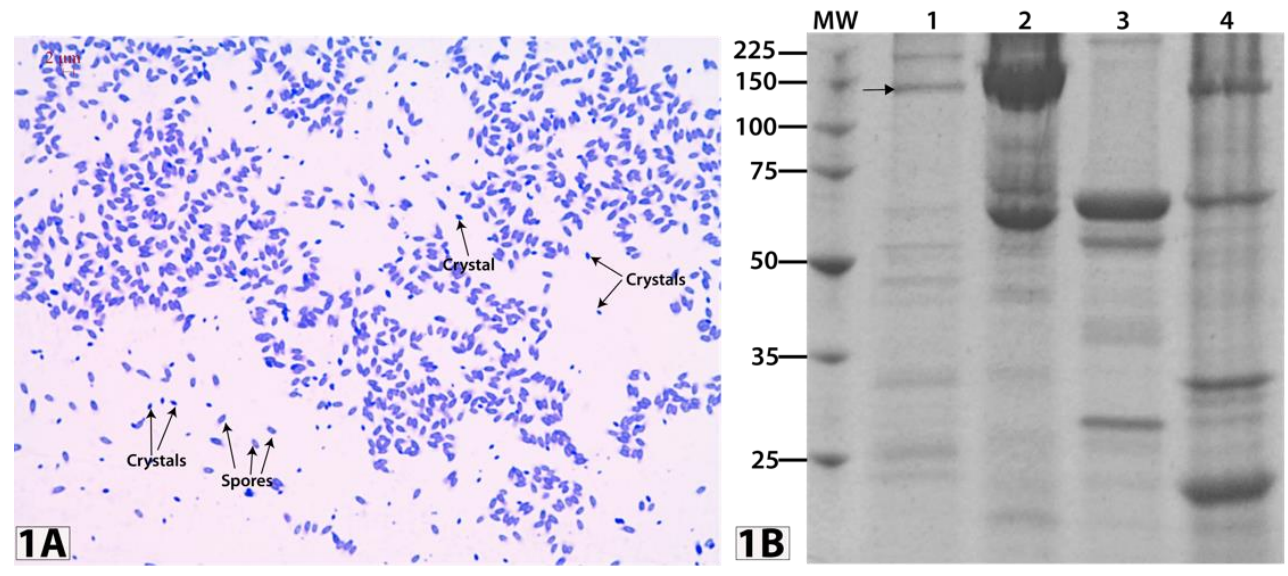
Figure 1. A) Morphological characterization of sporulated Bt-UNVM_94 strain. Parasporal crystals were stained with Coomassie brilliant blue $(1000 \times)$ [16]. B) Electrophoretic analysis of crystal proteins of Bt strains. MW: molecular weight marker, lane 1: strain Bt-UNVM_94; lane 2: Bt svar. kurstaki strain HD-1; lane 3: Bt svar. morrisoni strain tenebrionis DSM2803 and lane 4: Bt svar. israelensis strain HD-567. Black arrow marks Cry7Ga-like protein band.

\subsection{Genome Sequencing and Analysis}

The Illumina raw reads ( $>23$ million) were trimmed and assembled into 43 contigs totalling 6,136,970 bp, with a $\mathrm{G}+\mathrm{C}$ content of $34,9 \%$. Genome annotation was performed with the NCBI Prokaryotic Genome Annotation Pipeline (2018 release) although it was also annotated with RAST [17]. Annotated genome sequence contained 6,309 predicted protein-coding genes plus 86 RNAs.

Bt-UNVM_94 harbours one CDS (coding sequence) showing 92\% pairwise identity with crystal protein Cry7Ga1 plus another CDSs showing 97\% pairwise identity with an Mpp (ETX/MTX2 family) pore forming protein from Bt (GenBank Accession Number WP_065212007). This CDS also showed $42 \%$ pairwise similarity with Beta pore-forming pesticidal protein Mpp2Aa3 at Bacterial Pesticidal Protein resource Centre [5]. Interestingly, we also found a third CDs showing $95 \%$ pairwise identity with a putative mosquitocidal protein from B. cereus (GenBank Acc. No. EEL19614).

The predicted gene encoding the Cry7Ga-like protein from strain Bt-UNVM_94 is $3,396 \mathrm{bp}$ in size encoding an amino acid sequence of 1,131 residues and accounting for a molecular weight of $\sim 128 \mathrm{kDa}$. This Cry7Ga-like protein sequence is identical in size and molecular weight to the three domain Cry7Ga1 protein but showed a slightly longer Endotoxin_N conserved domain (InterPro ID IPR005639) with 12 ungapped amino acid residues (58-ISLLLNKLLSIL-69), located towards the N-terminus of the protein (Figure 2). This Endotoxin_N domain has been described to participate into membrane insertion and pore formation [2] whereas both domain Endotoxin_M (InterPro ID IPR001178) and Endotoxin_C (InterPro ID IPR005638) are widely accepted to be involved in receptor binding [18]. This protein sequence also showed a Cry1Ac_D5 conserved domain (InterPro ID IPR041587) toward the C-terminus. This conserved domain is found at the protoxin portion of some crystal proteins such as Cry1Ac [19].

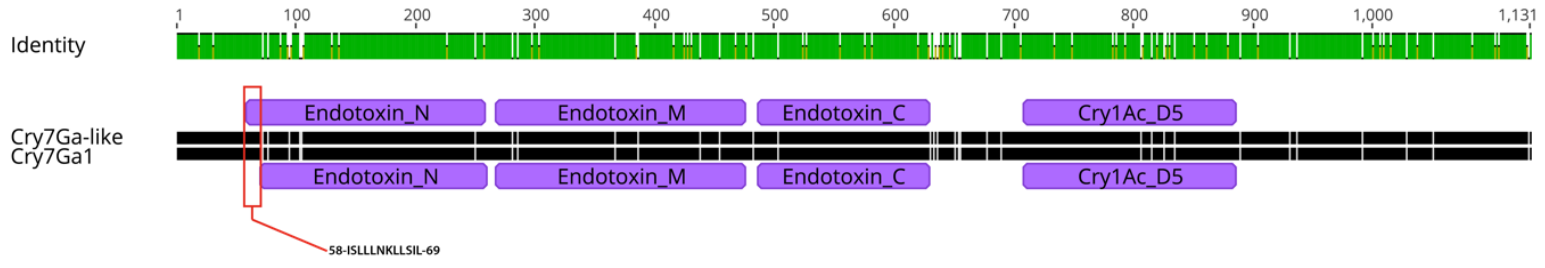

Figure 2. Schematic representation of novel Cry7Ga-like protein from strain Bt-UNVM_94 and reference Cry7Ga1 protein. Purple rectangles represent Pfam [20] conserved domains predicted with InterProScan, namely: Endotoxin_N (N-terminal domain), conserved domain involved in membrane insertion and pore formation, Endotoxin_M (central domain) and Endotoxin_C (Cterminal domain)=involved in receptor binding. Cry1Ac_D5 domain is also showed towards the Cterminus. Identity graph represents pairwise identity over all pairs in the column (green 100\% identity, greeny-brown at least $30 \%$ and under $100 \%$ identity and red, below $30 \%$ identity). Red rectangle depicts Endotoxin_N extension located at Cry7Ga-like protein. .

The Mpp coding sequence is $912 \mathrm{bp}$ long and encodes a predicted protein sequence of 303 amino acids with a molecular weight of $\sim 33 \mathrm{kDa}$. InterProScan search predicted a putative signal peptide from residues 1 to 33 and an aerolysin-like ETX_MTX2 pore forming conserved domain from residues 84 to 290 (InterPro ID IPR004991).

The putative mosquitocidal protein CDs is $1,548 \mathrm{bp}$ long and encodes a predicted protein of 515 amino acids with a molecular weight of $\sim 57 \mathrm{kDa}$. Conserved domain search with InterProScan showed a putative signal peptide sequence from residues 1 to 19 , an NPP1 necrosis inducing protein conserved domain (InterPro ID IPR008701) from residues 
50 to 253 and a RicinB_lectin_2 (InterPro ID IPR000772) conserved domain from residues 302 to 391 .

No protein bands of $\sim 33$ and $\sim 57 \mathrm{kDa}$ corresponding to predicted Mpp or the mosquitocidal toxin, respectively, were observed in the SDS-PAGE gel (Figure 1).

\subsection{Bioassays and Insecticidal Activity}

Mixed spore-crystal suspensions of strain Bt-UNVM_94 exhibited dual toxicity with $50 \%$ and $91 \%$ mortality against C. pomonella (Lepidoptera: Tortricidae) and A. grandis (Coleoptera: Curculionidae), respectively.

\section{Discussion}

To date, Bt remains as the most successfully used bacterium for the biological control of insect pests in agriculture. However, the most significant number of characterized $\mathrm{Bt}$ strains and their insecticidal proteins have been reported to be active against lepidopteran pests [13]. A smaller fraction of known Bt proteins have been described to show coleopteran toxicity, including: Cry3, Cry7 and Cry8 proteins [13]. Specifically, Cry7A and Cry7B have been described for showing distinct toxic activity against coleopteran and lepidopteran larvae, respectively [3].

There was not any information available concerning the insecticidal activity or the host range for Cry7G proteins from Bt. Strain Bt-UNVM_94 has shown dual toxicity against both lepidopteran and coleopteran pests. The Mpp and Npp family proteins appear to have signal sequences and their corresponding bands do not appear in the SDS PAGE analysis using Bt-UNVM_94 spore-crystal mixtures. As a result, we believe that the toxicity data are likely to represent the first reported insecticidal activity for a Cry7G-like protein (although we cannot rule out the other proteins in the observed insecticidal activity). Therefore, further studies need to be performed (e.g., by cloning and independent expression) in order to determine the roles of each predicted protein in the insecticidal activity of strain Bt-UNVM_94.

\section{Materials and Methods}

\subsection{Bt Strain Isolation and Characterization}

The Bt-UNVM_94 strain was isolated from soil samples collected in the province of Santa Fe, Argentina, by following the methodology described by Palma (2015). The samples were obtained with a tubular soil sampler and consisted of $\sim 20 \mathrm{~g}$ of soil. After collection procedure, samples were stored at $4{ }^{\circ} \mathrm{C}$ in zip-lock bags until axenic isolation was performed [21]. Each sporulated culture was then heat fixed onto a glass microscope slide and stained with a Coomassie blue solution (0,133\% Coomassie Blue stain in $50 \%$ acetic acid) [16]. The identification of Bt-like parasporal crystals was performed by microscopic examination The composition of Bt-UNVM_94 crystal proteins was determined by SDSPAGE following the procedure described by Pérez et al. (2017). Bt svar. kurstaki strain HD1, Bt svar. morrisoni strain tenebrionis DSM2803 and Bt svar. israelensis strain HD-567 were used as reference [22].

\subsection{DNA Purification, Sequencing and Genome Sequence Analysis}

Total DNA isolation (chromosome and plasmids) was performed using the Wizard genomic DNA purification kit (Promega) and purified DNA sequenced at Stabvida (Portugal) by using high-throughput Illumina sequencing technology with a genomic coverage of $1000 \times$ [23]. The raw Illumina reads obtained were first trimmed and assembled in contigs by using Geneious R11 (www.geneious.com), with the de novo assembly tool and default parameters. The resultant contigs were then analysed BLAST [24] using a customized non-redundant insecticidal toxin database. Genome annotation was performed with the NCBI Prokaryotic Genome Annotation Pipeline (2018 release) although it was also annotated with RAST [17]. Multiple sequence alignments and conserved domain searches were performed using suitable tools included in Geneious R11 [25]. 


\subsection{Bioassays and Insecticidal Activity}

The insecticidal activity of concentrated spore-crystal suspensions were assessed by the diet incorporation method using neonate larvae of Cydia pomonella L. (Lepidoptera: Tortricidae) and Anthonomus grandis B. (Coleoptera: Curculionidae) at concentrations of 5 and $1000 \mu \mathrm{g} / \mathrm{mL}$, respectively.

Author Contributions: Conceptualization, C.P., D.H.S., P.C., C.B. and L.P.; methodology, C.P., D.H.S., C.B., E.E.D.V. and L.P.; software, L.P. and J.C; validation, C.P., D.H.S., P.C., A.F., C.B. and L.P.; formal analysis, C.P, D.H.S. and L.P.; investigation, C.P, D.H.S., M.P, M.I.O, A.F, J.C., P.C., C.B., E.E.D.V. and L.P.; resources, D.H.S, P.C, E.E.D.V. and L.P.; data curation, L.P.; writing-original draft preparation, C.P., D.H.S, C.B and L.P; writing-review and editing, C.P., D.H.S, C.B. and L.P; visualization, C.P, D.H.S and L.PL.; supervision, D.H.S., C.B. and L.P.; project administration, P.C and L.P.; funding acquisition, P.C and L.P. All authors have read and agreed to the published version of the manuscript.", please turn to the CRediT taxonomy for the term explanation. Authorship must be limited to those who have contributed substantially to the work reported.

Funding: This research was funded by grant PIC-UNVM 2017-2019 from Universidad Nacional de Villa Maria, grant 2017 ‘Universidades Agregando Valor' res. 3052/16 from Secretaría de Políticas Universitarias and grant PICT-2017-0087 from Fondo para la Investigación Científica y Tecnológica (FONCyT).

Acknowledgments: We also thanks to Gustavo Chacón from Formulagro S.R.L. (Argentina) as a company personnel representative at "Universidades, Agregando Valor" grant application.

Conflicts of Interest: The authors declare no conflict of interest.

\section{References}

1. Lacey, L.A.; Grzywacz, D.; Shapiro-Ilan, D.I.; Frutos, R.; Brownbridge, M.; Goettel, M.S. Insect pathogens as biological control agents: Back to the future. J. Invertebr Pathol 2015, 132, 1-41, doi:10.1016/j.jip.2015.07.009.

2. Schnepf, E.; Crickmore, N.; Van Rie, J.; Lereclus, D.; Baum, J.; Feitelson, J.; Zeigler, D.R.; Dean, D.H. Bacillus thuringiensis and its pesticidal crystal proteins. Microbiol Mol. Biol Rev. 1998, 62, 775-806.

3. van Frankenhuyzen, K. Insecticidal activity of Bacillus thuringiensis crystal proteins. J. Invertebr Pathol 2009, 101, 1-16, doi:10.1016/j.jip.2009.02.009.

4. van Frankenhuyzen, K. Cross-order and cross-phylum activity of Bacillus thuringiensis pesticidal proteins. J. Invertebr Pathol 2013, 114, 76-85, doi:10.1016/j.jip.2013.05.010.

5. Crickmore, N.; Berry, C.; Panneerselvam, S.; Mishra, R.; Connor, T.R.; Bonning, B.C. A structure-based nomenclature for Bacillus thuringiensis and other bacteria-derived pesticidal proteins. J. Invertebr Pathol 2020, 10.1016/j.jip.2020.107438, 107438, doi:10.1016/j.jip.2020.107438.

6. Berry, C. The bacterium, Lysinibacillus sphaericus, as an insect pathogen. J. Invertebr Pathol 2012, 109, 1-10, doi:10.1016/j.jip.2011.11.008.

7. Palma, L.; Muñoz, D.; Berry, C.; Murillo, J.; Caballero, P. Bacillus thuringiensis toxins: An overview of their biocidal activity. Toxins (Basel) 2014, 6, 3296-3325, doi:10.3390/toxins6123296.

8. Jurat-Fuentes, J.L.; Crickmore, N. Specificity determinants for Cry insecticidal proteins: Insights from their mode of action. J. Invertebr Pathol 2017, 142, 5-10, doi:10.1016/j.jip.2016.07.018.

9. de Maagd, R. Bacillus thuringiensis-Based Products for Insect Pest Control. In: Lugtenberg B. (eds) Principles of Plant-Microbe Interactions. Springer, Cham. 2015.

10. Porcar, M.; Juárez-Pérez, V. PCR-based identification of Bacillus thuringiensis pesticidal crystal genes. FEMS microbiology reviews 2003, 26, 419-432.

11. Hernández-Rodríguez, C.S.; Boets, A.; Van Rie, J.; Ferré, J. Screening and identification of vip genes in Bacillus thuringiensis strains. Journal of applied microbiology 2009, 107, 219-225, doi:10.1111/j.1365-2672.2009.04199.x.

12. Palma, L.; Ruiz de Escudero, I.; Maeztu, M.; Caballero, P.; Muñoz, D. Screening of vip genes from a Spanish Bacillus thuringiensis collection and characterization of two novel Vip3 proteins highly-toxic to five lepidopteran crop pests. Biol control 2013, 66, 141149.

13. Dominguez-Arrizabalaga, M.; Villanueva, M.; Escriche, B.; Ancin-Azpilicueta, C.; Caballero, P. Insecticidal Activity of Bacillus thuringiensis Proteins Against Coleopteran Pests. Toxins (Basel) 2020, 12, doi:10.3390/toxins12070430. 
14. Peralta, C.; Palma, L. Is the insect world overcoming the efficacy of Bacillus thuringiensis? Toxins (Basel) 2017, 9, 1-5, doi:10.3390/toxins9010039.

15. Peralta, C.; Sauka, D.H.; Marozzi, A.; Del Valle, E.E.; Palma, L. Argentinean Bacillus thuringiensis strains exhibiting distinct morphology of their parasporal crystals. Rev. Argent. Microbiol 2020, 10.1016/j.ram.2020.09.005, doi:10.1016/j.ram.2020.09.005.

16. Ammons, D.; Rampersad, J.; Khan, A. Usefulness of staining parasporal bodies when screening for Bacillus thuringiensis. J. Invertebr Pathol 2002, 79, 203-204, doi:10.1016/s0022-2011(02)00018-6.

17. Aziz, R.K.; Bartels, D.; Best, A.A.; DeJongh, M.; Disz, T.; Edwards, R.A.; Formsma, K.; Gerdes, S.; Glass, E.M.; Kubal, M., et al. The RAST server: Rapid annotations using subsystems technology. BMC genomics 2008, 9, 1-15, doi:10.1186/1471-2164-9-75.

18. Bravo, A.; Gill, S.S.; Soberón, M. Mode of action of Bacillus thuringiensis Cry and Cyt toxins and their potential for insect control. Toxicon: Official journal of the International Society on Toxinology 2007, 49, 423-435, doi:10.1016/j.toxicon.2006.11.022.

19. Evdokimov, A.G.; Moshiri, F.; Sturman, E.J.; Rydel, T.J.; Zheng, M.; Seale, J.W.; Franklin, S. Structure of the full-length insecticidal protein Cry1Ac reveals intriguing details of toxin packaging into in vivo formed crystals. Protein Sci 2014, 23, 14911497, doi:10.1002/pro.2536.

20. Mistry, J.; Chuguransky, S.; Williams, L.; Qureshi, M.; Salazar, G.A.; Sonnhammer, E.L.L.; Tosatto, S.C.E.; Paladin, L.; Raj, S.; Richardson, L.J., et al. Pfam: The protein families database in 2021. Nucleic Acids Res. 2020, 10.1093/nar/gkaa913, doi:10.1093/nar/gkaa913.

21. Palma, L. Protocol for the fast isolation and identification of insecticidal Bacillus thuringiensis strains from soil. Bt Research 2015, 6, 1-3.

22. Perez, M.P.; Sauka, D.H.; Onco, M.I.; Berretta, M.F.; Benintende, G.B. Selection of Bacillus thuringiensis strains toxic to cotton boll weevil (Anthonomus grandis, Coleoptera: Curculionidae) larvae. Rev. Argent. Microbiol 2017, 49, 264-272, doi:10.1016/j.ram.2016.12.010.

23. Caballero, J.; Peralta, C.; Molla, A.; Del Valle, E.E.; Caballero, P.; Berry, C.; Felipe, V.; Yaryura, P.; Palma, L. Draft genome sequence of Bacillus cereus CITVM-11.1, a strain exhibiting interesting antifungal activities. Journal of Molecular Microbiology and Biotechnology (in press) 2018.

24. Altschul, S.F.; Gish, W.; Miller, W.; Myers, E.W.; Lipman, D.J. Basic local alignment search tool. J. Mol. Biol. 1990, 215, 403-410, doi:10.1016/S0022-2836(05)80360-2.

25. Drummond, A.J.; Ashton, B.; Buxton, S.; Cheung, M.; Cooper, A.; Duran, C.; Field, M.; Heled, J.; Kearse, M.; Markowitz, S., et al. Geneious R11. Available online: http://www.geneious.com/ (accessed on: 14 January 2021). 